\title{
Optimization of Ozone Generation by Investigation of Filament Current Characteristics under Dielectric Barrier Discharge
}

\author{
Yingjia Zhou, Guangming Huang, Tao Wang, Scott J. MacGregor, Senior Member, IEEE, \\ Qingchun Ren, Mark P. Wilson, Member, IEEE, Igor V. Timoshkin, Senior Member, IEEE
}

\begin{abstract}
In this paper, the relationship between reduced electric field and ozone efficiency was determined between $\sim 120$ Td and $\sim 280 \mathrm{Td}$, with an optimized efficiency of $\sim 207 \mathrm{~g} / \mathrm{kWh}$ at $\sim 123$ Td. An equivalent circuit with stray capacitance was used to analyze the filament current in the barrier discharge. The statistical distribution of the filament currents was found to change with different conditions, observing a decreased mean amplitude and narrower distribution with increased pressure and barrier thickness. Under the same reduced electric field, higher ozone efficiency was achieved at lower current and narrower distribution.
\end{abstract}

Index Terms - Dielectric barrier discharge, nonthermal plasma, filament current, ozone generation.

\section{INTRODUCTION}

$\mathrm{O}$ zone has been widely used in medical and industrial applications. It can be produced by a two-step process: i) generation of free oxygen atoms by ionization; and ii) generation of ozone by the combination of oxygen atoms with oxygen molecules [1] through the reactions (1) to (2) coming with the unavoidable dissociation processes by the reactions (3) to (4) [2]-[4].

$$
\begin{gathered}
O_{2}+e \rightarrow 2 O+e \\
O_{2}+O+M \stackrel{k_{1}}{\rightarrow} O_{3}+M \\
k_{1}=6.0 \times 10^{-34}\left(\frac{T}{300}\right)^{-2.6} \mathrm{~cm}^{3} /(\mathrm{mol} \times \mathrm{s}) \\
O_{3}+e \rightarrow \text { Products } \\
O+O_{3} \stackrel{k_{2}}{\rightarrow} 2 O_{2} \\
k_{2}=8.0 \times 10^{-12} \exp \left(-\frac{2060}{T}\right) \mathrm{cm}^{3} /(\mathrm{mol} \times \mathrm{s})
\end{gathered}
$$

A dielectric barrier discharge is a type of non-thermal plasma

This paper is submitted for review on $30^{\text {th }}$ November, 2015 .

All the authors are with the Department of Electronic and Electrical Engineering, University of Strathclyde, Royal College Building, 204 George Street, Glasgow, UK, G1 1XW (email: yingjia.zhou@strath.ac.uk). discharge, via which a pulsed current can be effectively developed between two metallic electrodes, separated by a dielectric [2]-[3]. Dielectric barrier discharges can efficiently limit the charge transfer associated with a discharge event, as well as distribute the generated plasma over the entire dielectric barrier surface. Once the electric field across the inter-electrode gap space is strong enough, an electron avalanche develops. Assuming that the radius of the avalanche head $r_{a} \approx 1 / \alpha$, the Meek breakdown criterion requires that $\alpha d \geq 20$, a streamer discharge develops [5]. With a dielectric barrier, the electrons or ions at the head of the streamer accumulate on the surface of the barrier, the local electric field in the filament is reduced which leads to the extinguishing of the filament.

At present, the typical commercial efficiency of ozone generators is $90 \mathrm{~g} / \mathrm{kWh}$ using dry air and $180 \mathrm{~g} / \mathrm{kWh}$ using oxygen [1]. These practical efficiencies are low compared to the theoretical efficiency of $1200 \mathrm{~g} / \mathrm{kWh}$, with $85 \%$ of the energy being lost as heat. In attempts to increase the ozone yield, some investigators have researched reactors cooled by liquid nitrogen [6]-[7]; the ozone efficiency achieved was in the range of $400-600 \mathrm{~g} / \mathrm{kWh}$.

The humidity effect on ozone generation has been investigated [8]-[10]. More recently, the photochemistry of $O_{3}$ generated by VUV has been characterised [11-12]. Using a xenon excimer lamp with central wavelength of $172 \mathrm{~nm}$, photons with energy of $7.22 \mathrm{eV}$ are generated; these photons can react efficiently with oxygen but does not dissociate ozone, allowing the reaction efficiency to reach $497 \mathrm{~g} / \mathrm{kWh}$ [11]. Moreover, pulse discharges of duration in the nanosecond regime can produce the ozone yield of $544 \mathrm{~g} / \mathrm{kWh}$ when oxygen-fed, and $239 \mathrm{~g} / \mathrm{kWh}$ when air-fed; with pulse duration of the order of nanoseconds, ion movement is efficiently restricted, reducing the energy loss [13]-[14]. New methods are being investigated to improve ozone efficiency.

\section{EXPERIMENTAL SETUP}

\section{A. Experimental Equipment}

A schematic diagram of the reactor is shown in Fig. 1. Two stainless steel (SS316) plates with $1 \mathrm{~mm}$ thickness and $30 \mathrm{~mm}$ diameter form the electrodes. A square glass cover, with $\varepsilon_{r}=6.7$, and a length of $50 \mathrm{~mm}$ is used as a dielectric barrier. Between the barrier and the high-voltage electrode, four 5 -mm-long square glass spacers (varies from $0.1 \mathrm{~mm}$ to $0.3 \mathrm{~mm}$ with $0.1 \mathrm{~mm}$ increment) are used to form the discharge 
gap. A 2-mm-diameter hole in the centre of the high-voltage electrode forms a gas inlet at the top of the reactor, in order to optimize the gas flow path.

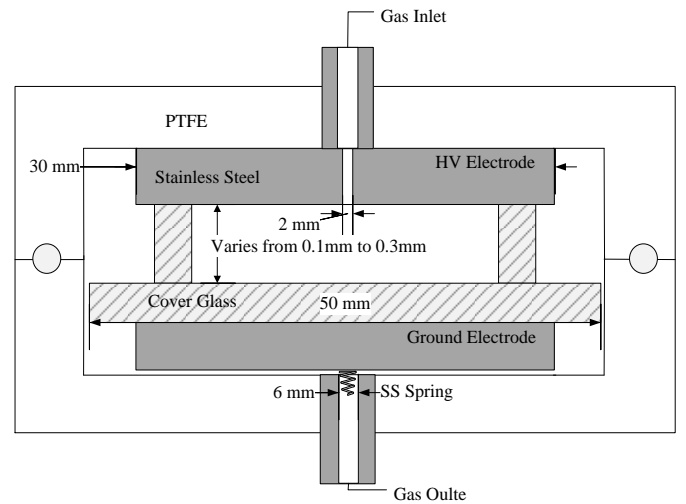

Fig. 1. Reactor design constructed with 30-mm diameter SS316 stainless-steel electrodes and 50-mm-long cover glass.

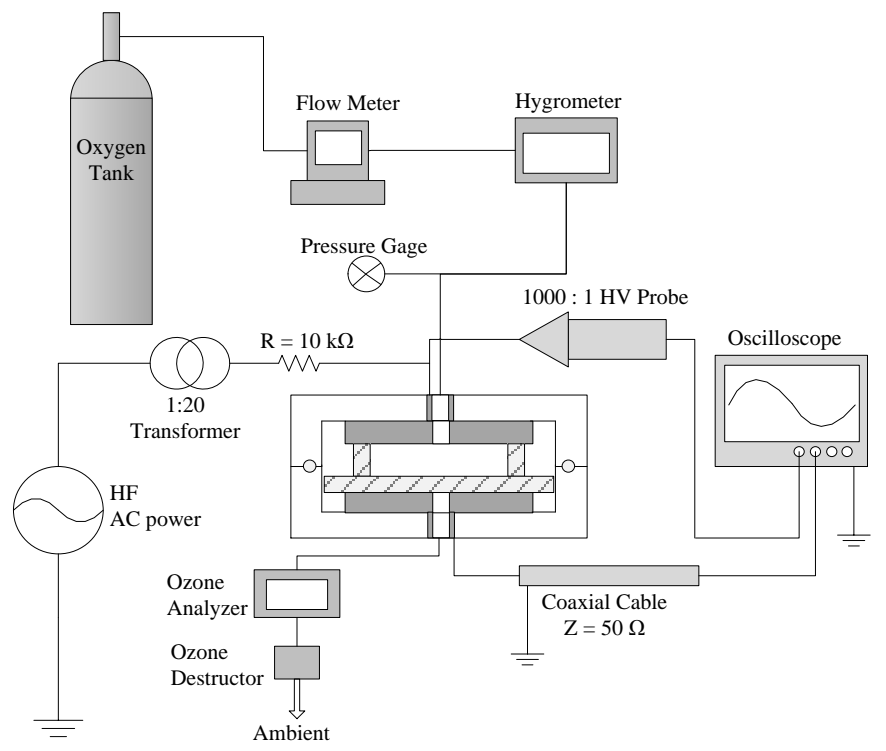

Fig. 2. Experimental arrangement.

Fig. 2 shows the experimental arrangement. A high-frequency $(5 \mathrm{kHz})$ power supply (Pacific Smart Source 112-AMX) was connected with a 1:20 transformer (up to 7 $\mathrm{kVac}$ ). A $10 \mathrm{k} \Omega$ current-limiting resistor is connected between the output of the transformer and the reactor. The ground electrode is connected to a digital storage oscilloscope (LeCroy WaveRunner $625 \mathrm{Zi}$ ) via a $50-\Omega$ coaxial cable. A high-voltage probe (Tektronix P6015A, 1000:1, $3.0 \mathrm{pF}, 100 \mathrm{M \Omega}$ ) is connected in parallel with the reactor to measure the input voltage. The current output is measured by an RS 405 coaxial cable (18 GHz bandwidth and $50 \Omega$ impedance) connected to the ground electrode.

Before the gas inlet, a flow meter is added to control and maintain the gas flow rate at $0.4 \mathrm{slpm}$ and to measure the gas inlet temperature, and a hygrometer measures the gas humidity. A needle valve is added after the gas outlet to control the pressure in the reactor. After the needle valve, an ozone analyzer (BMT 964 up to 10,000 ppm) is connected to measure the ozone concentration. The feed gas is pure oxygen $(99.5 \%$ purity), the temperature of the inlet gas was at $29^{\circ} \mathrm{C}$, with a dew point of $-42{ }^{\circ} \mathrm{C}$.

According to the value of the absolute rate coefficients of reaction (2) and (4), an increase of gas temperature will lead to an increase in the rate of ozone dissociation [1], [15], while the ozone production rate will reduce. In order to achieve higher ozone generation efficiency, balancing the temperature in the reactor is, therefore, crucial. In this experiment, the power supply was only enabled for 100 cycles for each test, in order to minimize the influence of gas temperature.

\section{B. Ozone Concentration Measurement}

As the power supply was only energized for 100 cycles, the ozone concentration was logged by software every $0.2 \mathrm{~s}$. Fig. 3 shows the typical ozone concentration waveform for $0.2 \mathrm{~mm}$ barrier thickness and $0.2 \mathrm{~mm}$ gap length, with $3 \mathrm{kV}_{\text {peak }}$ supply voltage. The ozone production under 100 cycles input energy is given by (5), where $F L$ is the oxygen flow rate, and $P P M_{V}$ is the ozone concentration measured in real-time.

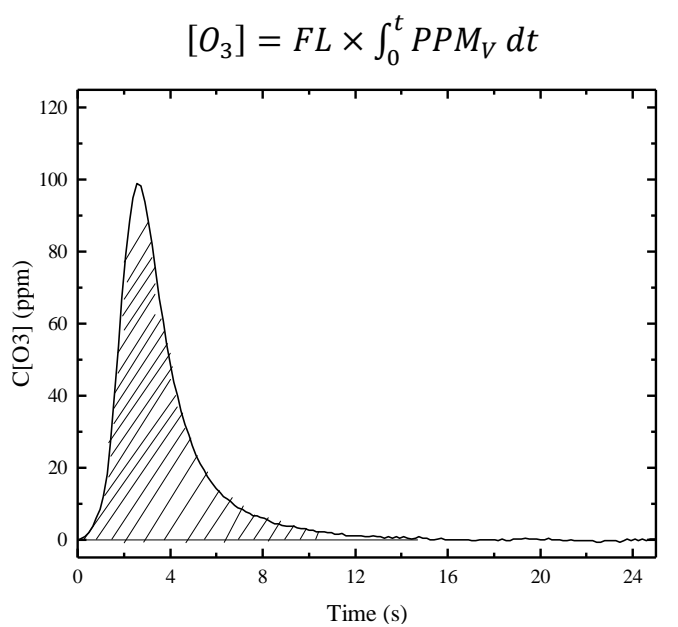

Fig. 3. Ozone concentration with $0.2 \mathrm{~mm}$ barrier thickness and $0.2 \mathrm{~mm}$ gap length, with $3 \mathrm{kV}_{\text {peak }}$ voltage supply.

\section{Ozone Efficiency Measurement}

Lissajous figures were used to measure the discharge energy by adding a measurement capacitor, $C_{m}(10 \mathrm{nF})$, between the reactor and ground. To ensure accurate measurements, all 100 cycles of the applied voltage waveform and voltage across $C_{m}$ were recorded using the oscilloscope. In order to take into account transient effects when the power supply is enabled, the energy associated with all 100 cycles was measured using individual Lissajous figures. Fig. 4 shows the sampled Lissajous figure measured in the $1^{\text {st }}$ cycle.

Considering that the charge transfer per half-cycle is $2 Q$, half of the charges are used to neutralize the opposite polarity charges left by the last half-cycle. The other half of the charges will accumulate on the barrier surface. For a non-energized reactor, there is no charge on the barrier surface; once energized, the charge transfer for the first cycle is not balanced. From Fig. 4, the charge transfer is $234 \mathrm{nC}$ in the positive half-cycle, while the charge transfer of the negative half-cycle is $353 \mathrm{nC}$. In this case, there is an offset apparent in the Lissajous figure in the first few cycles. According to the experimental results, the charge transfer per half-cycle can be balanced over 3 full cycles. 


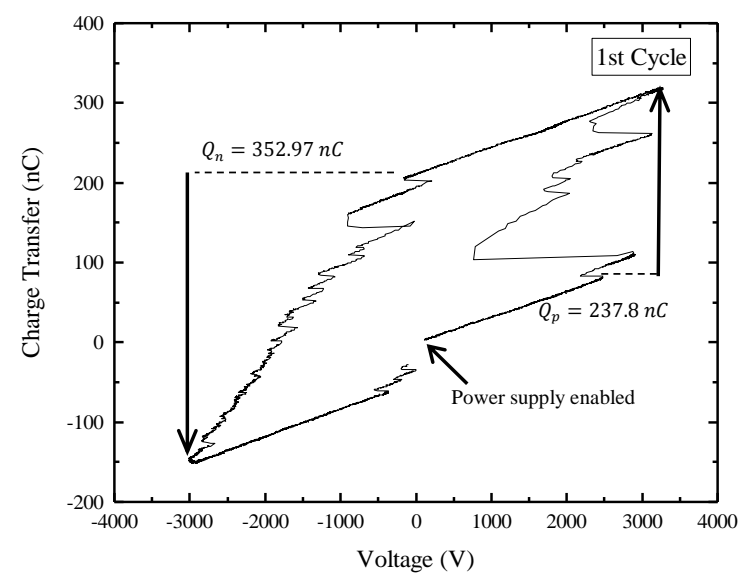

Fig.4. The sampled Lissajous figure of the $1^{\text {st }}$ cycle.

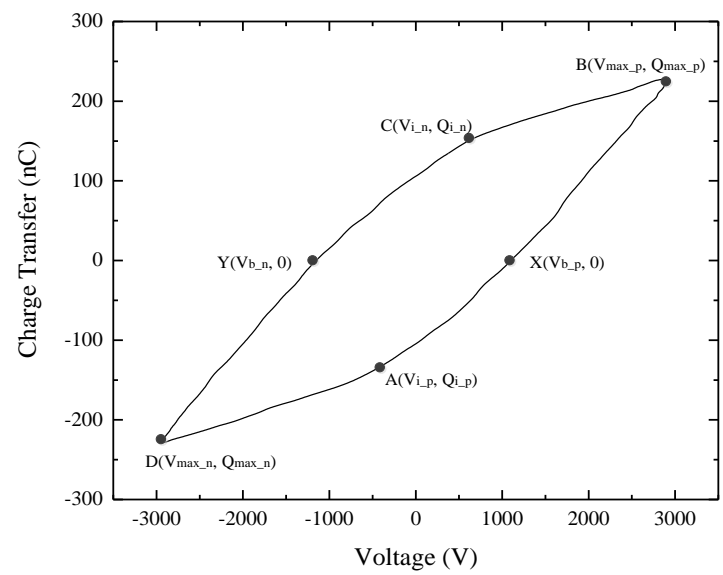

Fig. 5. Schematic of Lissajous figure to analyze the energy.

As a result, according to the six points identified in Fig. 5, the equivalent gap capacitance, $C_{g}$, the barrier capacitance, $C_{d}$, the breakdown voltage, $V_{b}$, and the maximum voltage, $V_{\max }$, of each cycle can be calculated. The energy of the $i^{\text {th }}$ cycle can be calculated using (6):

$$
E_{i}=4 C_{d_{-} i} V_{b_{-} i}\left(V_{\max _{\_} i}-\frac{C_{g_{-} i}+C_{d_{-} i}}{C_{d_{-} i}} V_{b_{-} i}\right)
$$

The total energy input for 100 cycles is calculated using (7):

$$
E_{\text {total }}=E_{1}+E_{2}+\cdots+E_{100}
$$

The ozone efficiency can then be calculated according to (8):

$$
\eta=\frac{\left[O_{3}\right]}{E_{\text {total }}}(g / k W h)
$$

\section{Current Measurement}

The current was measured by using a coaxial cable. Adding a current-limiting resistance can efficiently block the charging current from the power supply during the nanosecond discharge period, where the ionic current can be ignored [15].

A total of 10,000 individual current pulses were captured using the oscilloscope to analyze the mean amplitude, the rise-time $(30 \%$ to $90 \%)$ and the distributions of current amplitude.

\section{RESULTS}

The experimental results were gathered by measuring the ozone concentration and corresponding efficiency under varying voltage and gap length, to find the relationship between the reduced electric field $(E / N)$ and the ozone generation efficiency.

The ozone efficiency was investigated by changing the gap length from $0.1 \mathrm{~mm}$ to $0.3 \mathrm{~mm}$ with $0.1 \mathrm{~mm}$ increments and changing the peak amplitude of the supply voltage from $2 \mathrm{kV}$ to $3.5 \mathrm{kV}$ with $500-\mathrm{V}$ increments with $0.3 \mathrm{~mm}$ gap length. The results are shown in Fig. 6.

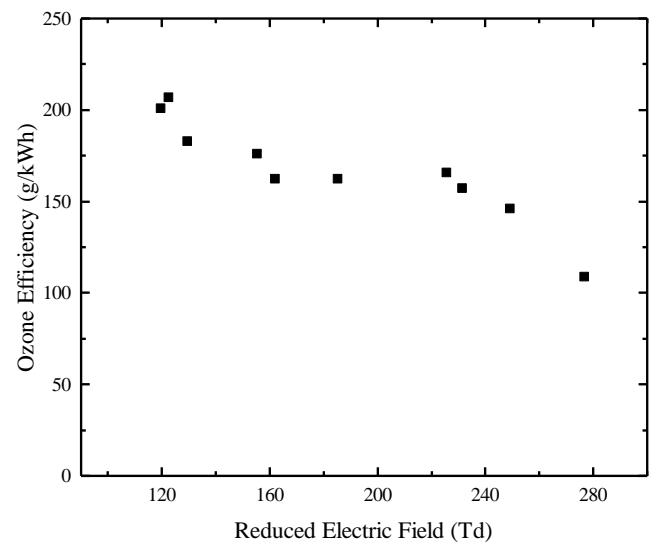

Fig. 6. The relationship between reduced electric field (Td) and ozone efficiency $(\mathrm{g} / \mathrm{kWh})$.

The optimized ozone efficiency reached in this experiment was $\sim 207 \mathrm{~g} / \mathrm{kWh}$, achieved when the reduced electric field was equal to $\sim 123 \mathrm{Td}$. With increase of the reduced electric field, the ozone efficiency dropped to $\sim 109 \mathrm{~g} / \mathrm{kWh}$ at $\sim 277 \mathrm{Td}$. The similar result was obtained by Kitayama demonstrating that the ozone efficiency reduces gradually with increasing the reduced electric field when $E / N \geq 100 T d$ [16].

With increasing reduced electric field, the electron energy increases also. The cross-section of oxygen ionization and dissociation increases dramatically [17], meaning that the number of electrons and $O$ atoms also increases.

In this case, the ozone concentration will increase. Meanwhile, as the reaction rate of the major ozone dissociation reaction (4) is a second-order reaction which is dependent on the concentration of both $O$ and $\mathrm{O}_{3}$, the ozone dissociation rate will also increase with increasing reduced electric field. In total, a reasonable $\mathrm{c}[\mathrm{O}] / \mathrm{c}\left[\mathrm{O}_{2}\right.$.] ratio is between $10^{-5}$ to $10^{-4}$. In this range, the conversion efficiency $\mathrm{c}\left[\mathrm{O}_{3}.\right] / \mathrm{c}[\mathrm{O}]$ can reach one [2].

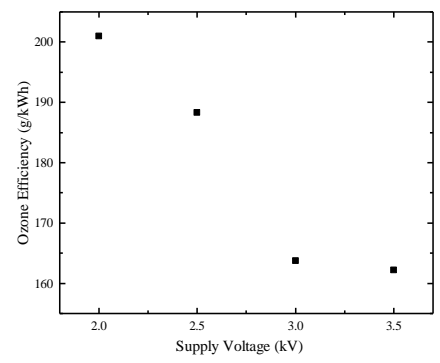

(a)

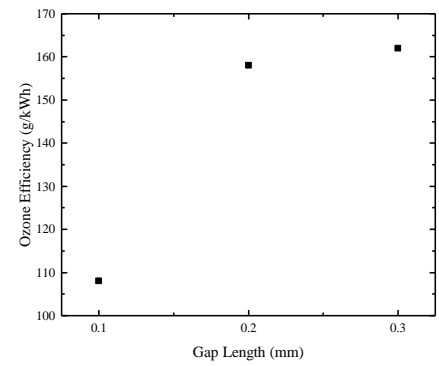

(b)
Fig. 7. (a) The relationship between the amplitude of the supply voltage (kV) and ozone efficiency $(\mathrm{g} / \mathrm{kWh})$ using $0.2 \mathrm{~mm}$ barrier thickness and $0.3 \mathrm{~mm}$ gap 
length, (b) the relationship between gap length $(\mathrm{mm})$ and ozone efficiency $(\mathrm{g} / \mathrm{kWh})$ with $3 \mathrm{kV}_{\text {peak }}$ voltage supply and $0.2 \mathrm{~mm}$ barrier thickness.

For a certain gap length and oxygen flow rate, increasing the supply voltage leads to an increase in the ozone concentration, while the ozone efficiency decreases. With $0.3 \mathrm{~mm}$ gap, the ozone efficiency was found to decrease from $\sim 201 \mathrm{~g} / \mathrm{kWh}$ to $\sim 162 \mathrm{~g} / \mathrm{kWh}$ with increasing supply voltage from $2 \mathrm{kV}$ to $3.5 \mathrm{kV}$ as shown in Fig. 7(a), with the ozone concentration increased from $164 \mathrm{ppm}$ to $397 \mathrm{ppm}$.

According to the Lissajous figures in Fig. 8, with increasing supply voltage, the breakdown voltage increases from $703 \mathrm{~V}$ to $1046 \mathrm{~V}$, and the equivalent barrier capacitance increases (while the depth of the gap remains $0.3 \mathrm{~mm}$ ). As the discharge in oxygen is filamentary [18], the electron distribution on the surface of the barrier is not uniform. With lower supply voltage, only a few discharges occur during the half-cycle - each discharge is relatively independent, with the charge accumulated on the surface being different each time. There exists a certain point of enhanced local electrical field where the discharge will occur first. With increasing supply voltage, the number of charges accumulated on the barrier surface increases and the distribution is more uniform, and the value of equivalent barrier capacitance increases. In this case, the breakdown voltage of the gap is closer to the breakdown voltage of a parallel-plane geometry, when there is no local field enhancement.

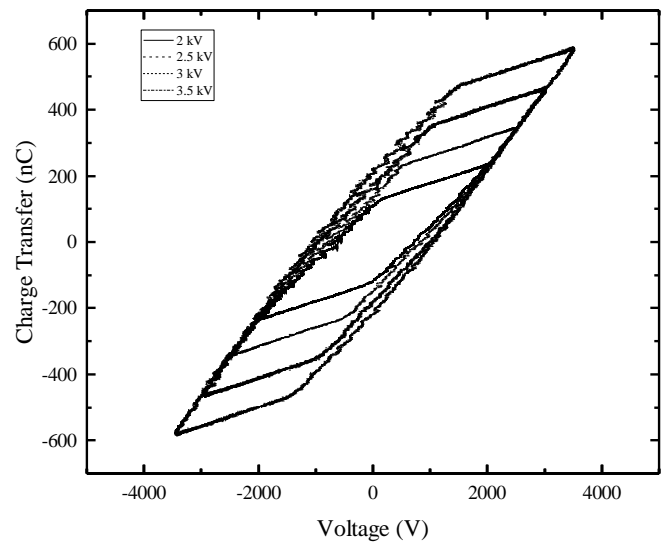

Fig. 8. Lissajous figures for different peak amplitude of supply voltage from $2 \mathrm{kV}$ to $3.5 \mathrm{kV}$, with $0.2 \mathrm{~mm}$ barrier thickness and $0.3 \mathrm{~mm}$ gap length.

For a given supply voltage, increasing the gap size from $0.1 \mathrm{~mm}$ to $0.3 \mathrm{~mm}$ leaded to an increase in both the ozone concentration and the ozone efficiency. For instance, under $3 \mathrm{kV}$ input voltage, the ozone efficiency increased from $\sim 109 \mathrm{~g} / \mathrm{kWh}$ to $\sim 162 \mathrm{~g} / \mathrm{kWh}$, and the ozone concentration increased from $198.5 \mathrm{ppm}$ to $337.0 \mathrm{ppm}$.

Increasing the gap length, the electric field decreases from $\sim 277 \mathrm{Td}$ to $\sim 145 \mathrm{Td}$ with $3 \mathrm{kV}_{\text {peak }}$ supply voltage as shown in Fig. 7(b); with increasing reduced electric field, the ozone concentration decreases. The input energy for the different gap-lengths studied here does not change much under the same supply voltage (from $0.10 \mathrm{~J}$ to $0.12 \mathrm{~J}$ ), while the ozone concentration decreases dramatically when the reduced electric field increases. In summary, it can be said that increasing the reduced electric field above the optimal value leads to a higher increase in the rate of ozone dissociation than the rate of ozone formation, resulting in reduced ozone efficiency.

Comparing these two parameters (gap size and supply voltage), the ozone generation efficiency decreases with increase of the reduced electric field in the range $\sim 123 \mathrm{Td}$ to $\sim 277$ Td.

\section{DISCUSSION}

As reduced electric field is not the only parameter that could affect the ozone efficiency, the filament current was also analyzed under different conditions by measuring the external current. To analyse the relationship between filament current and ozone efficiency, both current and corresponding ozone efficiency were measured for different pressures and different barrier thicknesses. For each experiment, 10,000 individual pulses were captured and the ozone efficiency was measured to analyse the behaviour of the external current under different conditions.

\section{A. Filament Current Analysis}

Analysing the circuit before the occurrence of a discharge, the reactor can be represented as two capacitances in series: the gap capacitance, $C_{g}$, and the dielectric barrier capacitance, $C_{d}$, labelled as $C_{t}$ (total capacitance). When the voltage is increased, and the local electrical field at one point in the gap-space exceeds the threshold field for breakdown, a pulse discharge of nanoseconds duration occurs; the diameter of the filament channel is in the range $0.1 \mathrm{~mm}$ to $1 \mathrm{~mm} \mathrm{[6].} \mathrm{At} \mathrm{this}$ time, the equivalent circuit of the reactor can be treated as four capacitances, as shown in Fig. 9. The gap capacitance in the filament channel is $C_{g}{ }^{\prime \prime}$. The corresponding capacitance of the charged part of the barrier is $C_{d}{ }^{\prime \prime}$. The capacitance associated with the remainder of the gap (excluding the filament channel), $C_{g}{ }^{\prime}$, is in series with the capacitance associated with the remainder of the barrier, $C_{d}{ }^{\prime}$. The label $C_{s}$ represents the stray capacitance. To simplify the circuit, the area which is not influenced by the discharge is labelled $C_{t}{ }^{\prime}$.

As the streamer discharge occurs in the gas-gap, the voltage across the filament channel drops. Due to the current-limiting resistor in series with the reactor, the power supply cannot replenish the voltage drop across $C_{g}{ }^{\prime \prime}$. In this case, the voltage across $C_{t}{ }^{\prime}$ and $C_{s}$ will drop to replenish the energy loss until the reversed electric field is strong enough to extinguish the filament. Here, from Fig. 9, the current flowing through the $C_{t}{ }^{\prime}$ sub-circuit is $I_{t}$, the current flowing through the $C_{s}$ sub-circuit is $I_{e}$, and the current supplied by $C_{g}{ }^{\prime \prime}$ is $I_{g}$. For a single filament, the total filament current is $I_{f}$, the corresponding filament current is (9):

$$
I_{f}=I_{e}+I_{t}+I_{g}
$$

According to Fig. 9, the external current, $I_{e}$, measured using a current probe is the current flowing through the stray capacitance, $C_{s}$. The voltage drop across $C_{t}{ }^{\prime}$ is the same as the voltage drop across the stray capacitance, As $C_{t}{ }^{\prime}$ is much greater than $C_{g}{ }^{\prime \prime}$ and $C_{d}{ }^{\prime \prime}$ in series, the value of $C_{t}{ }^{\prime}$ can be assumed as the total capacitance, $C_{t}$. In this case, the filament current can be rewritten as (10): 


$$
I_{f}=I_{e}+C_{t} \frac{d V_{a}}{d t}+C_{g}{ }^{\prime \prime} \frac{d V_{g^{\prime \prime}}}{d t}
$$

where $V_{a}$ is the applied voltage across the reactor and $V_{g}{ }^{\prime \prime}$ is the voltage across the $C_{g}{ }^{\prime \prime}$. Here, the integration of the current flowing through $C_{s}$ and $C_{t}{ }^{\prime}$ is the charge transferred onto the barrier surface, leading to a voltage increase across the barrier. When the voltage drop across $C_{g}{ }^{\prime \prime}$ and the filament reaches a certain level, the discharge will be extinguished. For a given reactor, $C_{s}$ is a fixed value.

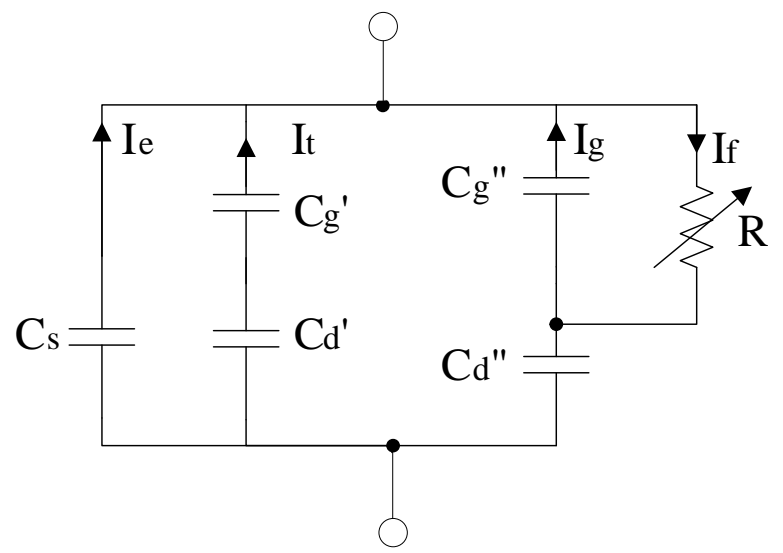

Fig. 9. Equivalent circuit for a single pulsed current.

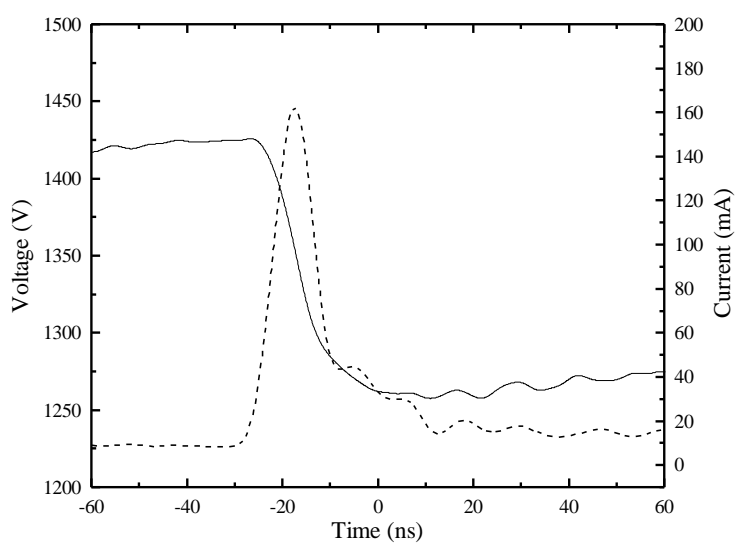

Fig.10. Single measured external current (dashed line) with corresponding voltage drops across the stray capacitance (solid line).

For a large ozone generator with total capacitance in the range of nano-Farads, the filament current can be approximated as the sum of $I_{e}$ and $I_{t}$. The distribution characteristics of the external current are identical to those of the filament current.

\section{B. Under Different Pressure}

With $0.3 \mathrm{~mm}$ gap length and $0.2 \mathrm{~mm}$ barrier thickness, the ozone efficiency was measured under various absolute pressures, from 1 bar to 1.6 bar, with 0.2 bar increments. The supply voltage was $3 \mathrm{kV}_{\text {peak }}$, and the frequency was $5 \mathrm{kHz}$. It can be clearly seen in Fig. 10 that with increasing pressure, the ozone efficiency increases, from $\sim 162 \mathrm{~g} / \mathrm{kWh}$ to $\sim 207 \mathrm{~g} / \mathrm{kWh}$.

Also shown in Fig. 11, the mean amplitude of the external current drops from $88 \mathrm{~mA}$ to $39 \mathrm{~mA}$ as the pressure is increased up to 1.6 bar. The rise time (30\% to $90 \%$ ) of the current pulse is relatively consistent, in the range from 3.2 ns to 3.3 ns. From this point of view, with low amplitude of the external current, the ozone efficiency can be increased. According to Braun's research [19], the pressure increase can reduce the filament radius therefore, decreasing the diffusion area of the accumulated ions on barrier surface for easier establishment of the reversed electric field. The corresponding filament current decreases.

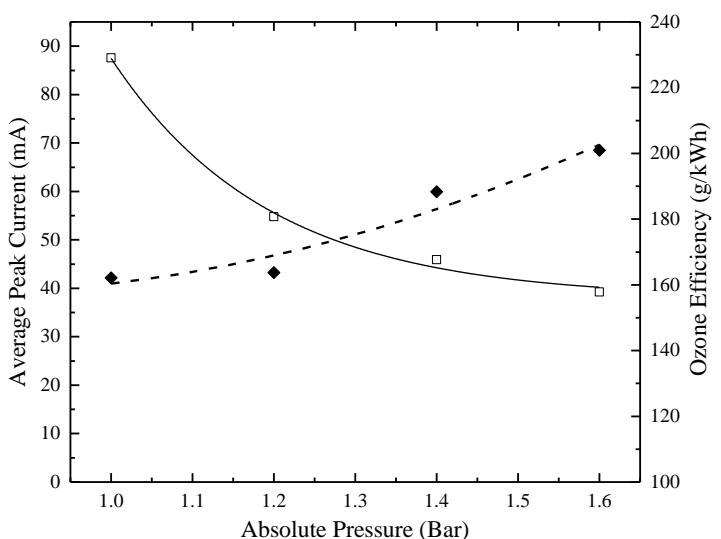

Fig. 11. Variation of average peak current (open squares and solid curve fit) and ozone efficiency (closed diamonds and dashed curve fit) with pressure. The dielectric barrier is $0.2 \mathrm{~mm}$ thick, and the gap length is $0.3 \mathrm{~mm}$ with $3 \mathrm{kV}_{\text {peak }}$ supply voltage.

From Fig. 12(a) and (b), the external measured current is lower under higher pressure. Zooming out these figures, it can be clearly seen that the repetition rate of discharge increases, while the voltage drop decreases dramatically. From Fig. 12(c) and (d), the histograms under different pressures display different current distributions. With increasing pressure, the current distribution becomes narrower, and the number of filaments with measured current between $20 \mathrm{~mA}$ and $40 \mathrm{~mA}$ is weighted at $83 \%$ at 1.6 bar. At 1 bar, although the most likely external current is also between $20 \mathrm{~mA}$ and $40 \mathrm{~mA}$, the total number of filaments with measured current in this range is only weighted at $37 \%$.

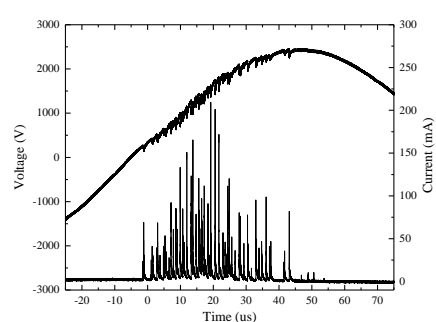

(a)

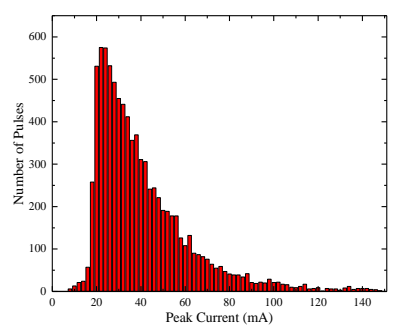

(c)

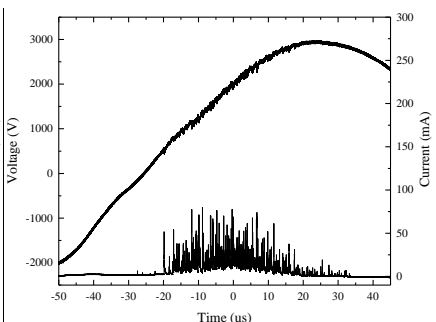

(b)

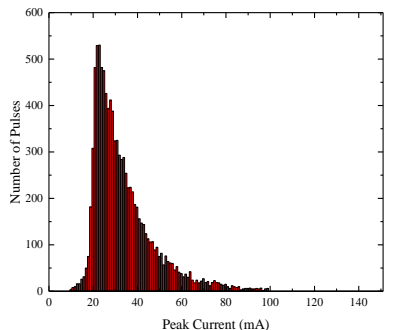

(d)
Fig. 12. The example quarter cycle waveform of voltage and current at (a) 1 bar and (b) 1.6 bar; and the histogram at (c) 1 bar and (d) 1.6 bar. The dielectric barrier is $0.2 \mathrm{~mm}$ thick, and the gap length is $0.3 \mathrm{~mm}$ with $3 \mathrm{kV}_{\text {peak }}$ supply voltage. 
Related with ozone efficiency distribution, it is confirmed that low amplitudes of the filament current can increase the ozone efficiency under the same experimental geometry and rector construction.

\section{Under Different Barrier Thickness}

To analyse the relationship between barrier thickness and ozone efficiency, experiments were carried out by changing the barrier thickness from $0.2 \mathrm{~mm}$ to $1 \mathrm{~mm}$, with a fixed gap length of $0.3 \mathrm{~mm}$.

From Fig. 13, the peak ozone efficiency with a 1-mm-thick barrier can reach $\sim 225 \mathrm{~g} / \mathrm{kWh}$ when the reduced electric field is $\sim 130 \mathrm{Td}$. Compared with the results with a 0.2 -mm-thick barrier, according to the fitting line, even under the same reduced electric field, the ozone efficiency increases with increasing barrier thickness. For instance, the ozone efficiency increases from $188 \mathrm{~g} / \mathrm{kWh}$ to $213 \mathrm{~g} / \mathrm{kWh}$ at $\sim 145 \mathrm{Td}$. Moreover, the ozone efficiency increases with increasing barrier thickness under the same input energy. For instance, with $0.13 \mathrm{~J}$ input energy, the ozone efficiency is increased from $\sim 162 \mathrm{~g} / \mathrm{kWh}$ at $0.2 \mathrm{~mm}$ to $\sim 185 \mathrm{~g} / \mathrm{kWh}$ at $1 \mathrm{~mm}$ barrier thickness under 1 bar absolute pressure.

Based on this finding, 10,000 individual current pulses were recorded, measuring the amplitude and the rise time of the external current, for analysis of the filament current. The results are shown in Fig. 14. When the pressure was increased from 1 bar to 1.6 bar with a 1 -mm-thick barrier, the average external current fell from $25 \mathrm{~mA}$ to $11 \mathrm{~mA}$. The rise times were all in the range from $3.9 \mathrm{~ns}$ to $4.2 \mathrm{~ns}$.

Fig. 15 shows the half-cycle voltage and current waveforms for $1 \mathrm{~mm}$ barrier thickness, $1 \mathrm{bar}$ absolute pressure and $6.5 \mathrm{kV}$ supply voltage. Compared with Fig. 12(a), the external current and the voltage drop are much lower for a thicker barrier, while the ozone efficiency is increased.

It is obvious that with increasing barrier thickness, the amplitude of the external current is decreased, while the ozone efficiency is increased. When ions accumulate on the surface of the barrier, there will be a redistribution of the electric field on the barrier. Some of the ions will build up the reversed electric field to halt the development of the filament, while the rest of the ions will form an electric field within the barrier to increase the voltage across the barrier. According to the equivalent circuit in Fig.9, for the same voltage drop across the filament channel, increasing the barrier thickness, both the barrier capacitance and total capacitance decrease making the corresponding current flowing through $C_{d}{ }^{\prime \prime}$ and the filament current reduced.

\section{Conclusions}

According to the Td versus ozone efficiency curve (Fig. 6), the ozone efficiency can reach $\sim 207 \mathrm{~g} / \mathrm{kWh}$ at $\sim 123 \mathrm{Td}$. The ozone efficiency then reduces gently when the reduced electric field is increased from $140 \mathrm{Td}$ to $210 \mathrm{Td}$. With continuing increase of the reduced electric field, the ozone efficiency fell rapidly to $\sim 109 \mathrm{~g} / \mathrm{kWh}$ at $\sim 277 \mathrm{Td}$.

For a single filament, the voltage drop across the filament channel leads to the extinguishing of the filament.
With increasing pressure, the current distribution becomes narrower and the mean amplitude of the filament current decreases, leading to higher ozone efficiency.

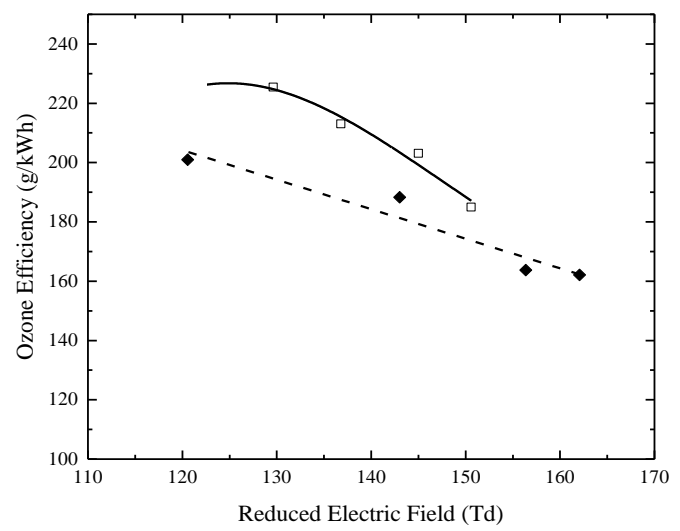

Fig. 13. The relationship between ozone efficiency and reduced electric field for a 1-mm barrier (open squares and solid line curve fit) and a $0.2-\mathrm{mm}$ barrier (closed diamonds and dashed line curve fit).

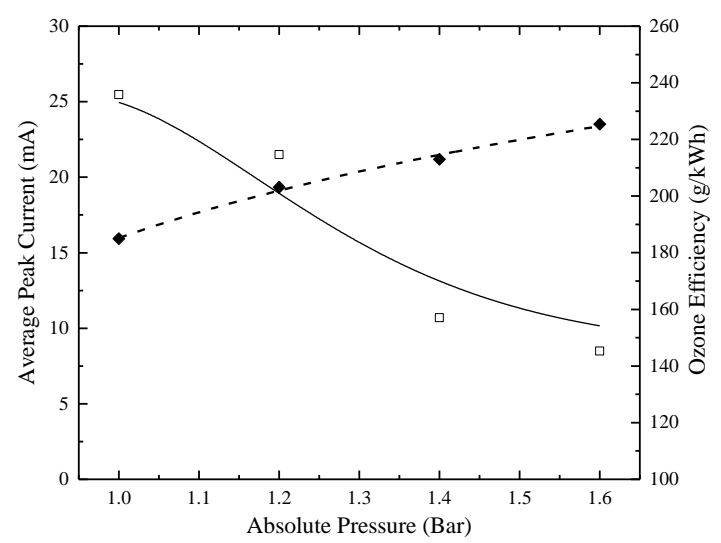

Fig. 14. Variation of average peak current (open squares and solid curve fit) and ozone efficiency (closed diamonds and dashed curve fit) with pressure. The dielectric barrier is $1 \mathrm{~mm}$ thick, and the gap length is $0.3 \mathrm{~mm}$.

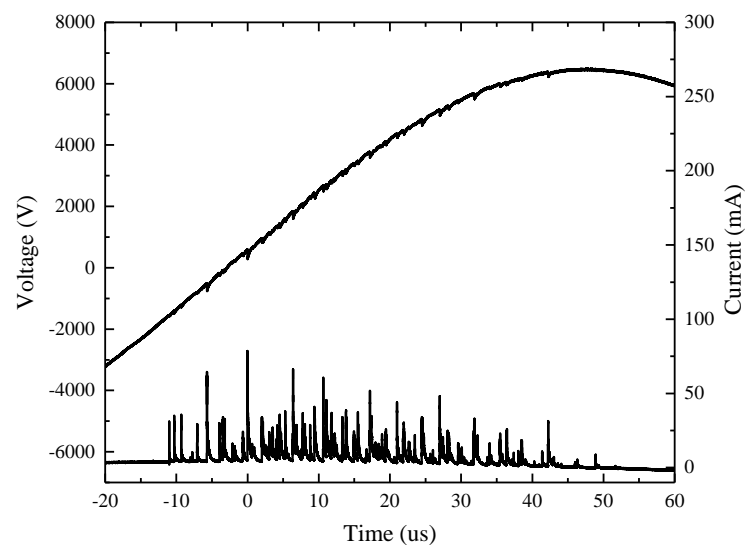

Fig. 15. Example quarter-cycle of current and voltage for $1 \mathrm{~mm}$ barrier, $0.2 \mathrm{~mm}$ gap length, with $6.5 \mathrm{kV}$ supply voltage.

For the same reduced electric field, with lower amplitude of the filament current and narrower current distribution, the ozone efficiency was found to increase as a result of more uniform distribution of the filaments on the barrier surface. The 
authors are currently working to figure out the values of $C_{g}{ }^{\prime \prime}$ and $C_{d}{ }^{\prime \prime}$ and the affected space area of each filament.

\section{REFERENCES}

[1] J.S. Chang. (1991, December). Corona Discharge Processes. IEEE Trans. Plasma Sci. [Online]. 19 (6), pp. 1152-1165. Available: http://dx.doi.org/10.1109/27.125038

[2] U. Kogelschatz. (1988). "Advanced Ozone Generation," Process Technologies for Water Treatment. Ed. Ssmuel Stucki. USA: Springer US. 1988. pp.87-120. Print.

[3] U. Kogelschatz. (1988, May). Ozone Generation From Oxygen And Air: Discharge Physics And Reaction Mechanisms. Ozone Sci Eng.[Online]. $10 \quad$ (4), pp. 367-378. Available: http://dx.doi.org/10.1080/01919518808552391

[4] R. Atkinson. (2004, September). Evaluated kinetic and photochemical data for atmospheric chemistry: Volume I- gas phase reactions of $O_{X}, H O_{X}, N O_{X}$ and $\mathrm{SO}_{X}$ species. Atoms. Chem. Phys. [Online]. $\quad 4, \quad$ pp1461-1738. Available: http://dx.doi.org/10.5194/acp-4-1461-2004

[5] A. Fridman. (2008). "Electric Discharges in Plasma Chemistry," Plasma Chemistry, $1^{\text {st }}$ ed. UK: Cambridge University Press. 2008.pp.157-258. [Online]. Available: http://dx.doi.org/10.1017/CBO9780511546075

[6] J.S. Chang. (1987, September). Mechanism of the ozone formations in a near liquid nitrogen temperature medium pressure glow discharge positive column. Presented at International Symposium on Plasma Chemistry. [Online]. Available: http://dx.doi.org/10.1351/pac198860050645

[7] S. Masuda. (1986). Production of ozone by surface and glow discharge at cryogenic temperatures. IEEE Trans. Industry Appl. [Online]. $24 \quad$ (5), $\quad$ pp 928-933. Available: http://dx.doi.org/10.1109/28.9000

[8] Z. Falkenstein. (1996, November). Microdischarge behaviour in the silent discharge of nitrogen-oxygen and water-air mixtures. J. Phys. D: Appl. Phys. [Online]. 30, pp.817-825. Available: http://dx.doi.org/10.1088/0022-3727/30/5/015

[9] R. Peyrous. (1989, November). Kinetic simulation of gaseous species created by an electric al discharge in dry or humid oxygen. J. Phys. D: Appl. Phys. [Online]. 22, pp. 1658-1667. Available: http://dx.doi.org/10.1088/0022-3727/22/11/015

[10] R. Peyrous. (1989, May). The Effect of Relative Humidity on Ozone Production by Corona Discharge in Oxygen or Air - A Numerical Simulation - Part I : Oxygen. Ozone Science and Engineering: Journal of the International Ozone Association. [Online]. 12 (1), pp. 19-40. Available: http://dx.doi.org/10.1080/01919519008552453

[11] M.J. Salvermoser. (2009 January). Influence of humidity on photochemical ozone generation with $172 \mathrm{~nm}$ xenon excimer lamps. Eur. Phys. J. Appl. Phys. [Online]. 47 (02). Available: http://dx.doi.org/10.1051/epjap/2009063

[12] M.J. Salvermoser. (2008, May- June). Influence of Water Vapor on Photochemical Ozone Generation with Efficient $172 \mathrm{~nm}$ Xenon Excimer Lamps. Ozone Science and Engineering. [Online]. 30 (3), pp 228-237. Available: http://www.tandfonline.com/doi/abs/10.1080/01919510802070611

[13] D.Y. Wang. (2010). "Pulsed Discharge Plasma for Pollution Control," Air Pollution, Ed. Vanda Villanyi. [Online]. Available: http://dx.doi.org/10.5772/10052

[14] N. Takamura. (2011, June). "Ozone generation using positive and negative nano-seconds pulsed discharges." Presented at Pulsed Power Conference. [Online]. Available: http://dx.doi.org/10.1109/PPC.2011.6191603

[15] B. Eliasson, M. Hirth, and U. Kogelschatz. (1987). Ozone synthesis from oxygen in dielectric barrier discharges. J. Phys. D: Appl. Phys., [Online]. vol. 20, no. 11, pp. 1421-1437. Available: http://dx.doi.org/10.1088/0022-3727/20/11/010

[16] J. Kitayama and M. Kuzumoto.(1997). Theoretical and experimental study on ozone generation characteristics of an oxygen-fed ozone generator in silent discharge. J. Phy. D: Appl. Phy. [Online]. vol. 30, p. 2453. Available: http://dx.doi.org/10.1088/0022-3727/30/17/011

[17] Y. Itikawa. (2009). Cross Sections for Electron Collisions with Oxygen Molecules, J. Phys. Chem. Ref. Data. [Online]. vol. 38(1). Available: http://dx.doi.org/10.1063/1.3025886
[18] U. Kogelschatz. (2002. Aug). Filamentary, patterned, and diffuse barrier discharges. IEEE Transactions on Plasma Science.[Online]. vol. 30(4). pp. 1400- $1408 . \quad$ Available: http://dx.doi.org/10.1109/TPS.2002.804201

[19] D. Braun. (1991, November). Microdischarges in air-fed ozonizers. J. Phys. D: Appl. Phys. [Online]. vol. 24, p.564-572. Available: http://dx.doi.org/10.1088/0022-3727/24/4/007

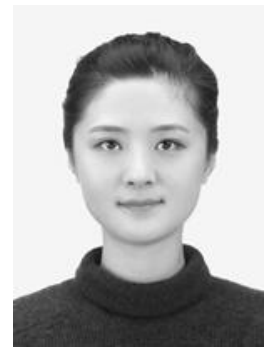

Yingjia. Zhou was born in Jiangsu Province, China, 1990. She received the Msc (Merit) Power System Engineering from University College London in 2013. Before that, she received B. Eng (First Class Hons) Electronic and Electrical Engineering from University of Strathclyde in 2012. From 2013, she has been a Ph.D. student under High Voltage Technologies group in the department of electronic and electrical engineering at University of Strathclyde. Her current research interest includes non-thermal plasma discharge applications such as ozone generation. Recently, she is working on the process of Dielectric Barrier Discharge.

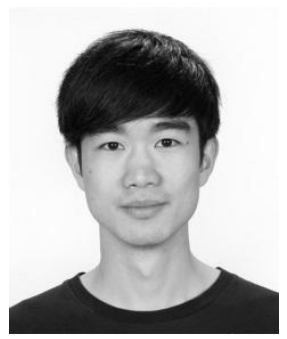

Guangming Huang received the B.Eng.(1st Class) degree in electronic and electrical engineering from the University of Strathclyde, Glasgow, UK. From 2010, he has been working toward the Ph.D. degree in the high voltage technology group in the department of electronic and electrical engineering at the University of Strathclyde. His Ph.D. research is focused on non-thermal plasma discharges for the ozone generation.

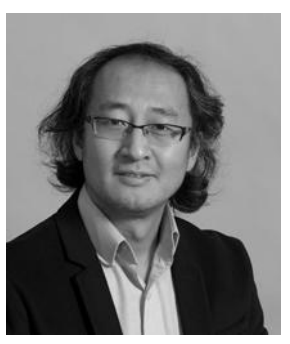

Tao Wang received the B.Eng and M.Sc degrees from Northeast China Dianli University (China) in 1993 and 1996 respectively, and the Ph.D. degree from the University of Strathclyde (Glasgow, UK) in 2005. He then joined the industry as a research fellow developing high efficiency industrial ozone generator. He joined the department of Electronic and Electrical Engineering of University of Strathclyde as a lecturer in 2010. His research interests include non-thermal gas discharges and their applications in gas synthesis, water disinfection and advanced oxidation process in water.

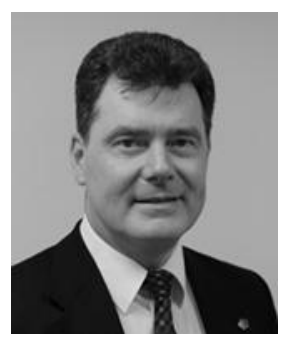

Scott J. MacGregor (M'95-SM'14) received the B.Sc. and Ph.D. degrees from the University of Strathclyde, Glasgow, U.K., in 1982 and 1986, respectively. He became a Pulsed Power Research Fellow in 1986 and a Lecturer in pulsed power technology in 1989. In 1994, he became a Senior Lecturer, with a promotion to Reader and Professor of High Voltage Engineering, in 1999 and 2001, respectively. From 2010 he became a Dean of the Engineering Faculty of the 
University of Strathclyde. His research interests include high-voltage pulse generation, high-frequency diagnostics, high-power repetitive switching, high-speed switching, electronic methods for food pasteurization and sterilization, generation of high-power ultrasound (HPU), plasma channel drilling, pulsed-plasma cleaning of pipes, and stimulation of oil wells with HPU.

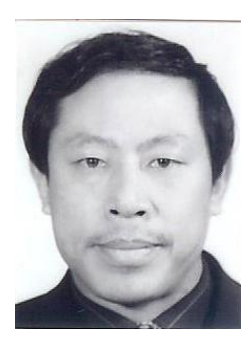

Qing Chun Ren is currently a senior research fellow in the Department of Electronic and Electrical Engineering at the University of Strathclyde. He has been working on ecological environment research and applications since his graduation from Tsinghua University (Beijing, China). His research interests include E-pack desalination techniques, nanofiber filters, treatment of high salinity and high organic content industrial wastewater, zero discharge wastewater treatment in cities and industrial estates.

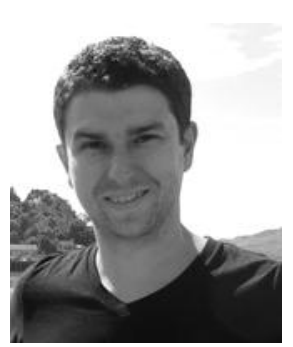

Mark P. Wilson (M'10) was born in Stranraer, Scotland, in 1982. He received the B.Eng. (with honours), M.Phil., and Ph.D. degrees in electronic and electrical engineering from the University of Strathclyde, Glasgow, U.K., in 2004, 2007, and 2011, respectively. $\mathrm{He}$ is presently working as a Teaching Associate at the University of Strathclyde, where he continues to investigate surface flashover of solids immersed in insulating oil. Mark is a member of the IEEE Nuclear and Plasma Sciences Society, from whom he received a Graduate Scholarship Award in 2011, the IEEE Dielectrics and Electrical Insulation Society, and the IET.

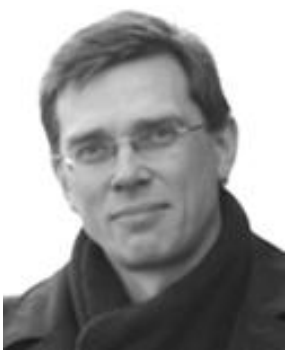

Igor V. Timoshkin (M'07-SM'14) received a degree in physics from the Moscow State University (Russia) in 1992, and the Diploma and the Ph.D. degree from the Imperial College of Science, Technology and Medicine, (London, UK) in 2001. After graduation from MSU he worked as a Researcher at Moscow State Agro-Engineering University, and then at the Institute for High Temperatures of Russian Academy of Sciences before moving to ICSTM in 1997. He joined the Department of Electronic and Electrical Engineering of the University of Strathclyde (Glasgow, UK) in 2001 where he became a Senior Lecturer in 2011. His research interests include properties of solid and liquid dielectric materials, electronics of plasma discharges in condensed media, practical applications of electro-hydraulic and high-power ultrasound pulses, bio-dielectrics and effects of electromagnetic fields on biological objects. 